\title{
Digestibilidade das dietas e metabolismo de suínos alimentados com dietas contendo bentonita sódica em diferentes programas alimentares
}

\author{
Digestibility of diets and metabolism of pigs fed with diets containing sodium bentonite in different \\ feeding programs
}

\author{
Cheila Roberta Lehnen ${ }^{I^{*}}$ Paulo Alberto Lovatto ${ }^{I I}$ Ines Andretta $^{\mathrm{I}}$ Carlos Augusto Rossi ${ }^{1}$ \\ Luciano Hauschild ${ }^{\mathrm{III}}$ Bruno Neutzling Fraga ${ }^{\mathrm{I}}$ Gerson Guarez Garcia ${ }^{\mathrm{II}}$
}

\section{RESUMO}

Foi realizado um experimento para avaliar a digestibilidade aparente de dietas e o metabolismo de suínos alimentados com dietas contendo bentonita sódica submetidos a diferentes programas alimentares. Foram utilizados 24 suínos machos castrados, meio irmãos paternos, com peso vivo médio inicial de 42,2 kg, alojados em gaiolas metabólicas. $O$ delineamento experimental foi o inteiramente casualizado com três níveis de bentonita sódica $(0,0 ; 0,3$ e $0,5 \%)$ e dois programas alimentares (restrito e à vontade), com oito repetições cada. A adição de bentonita sódica não alterou $(P>0,05)$ o consumo de ração e os balanços da energia e do nitrogênio. $O$ consumo de ração diferiu $(P<0,01)$ entre a alimentação restrita e à vontade $\left(1,17 \mathrm{vs} .2,19 \mathrm{~kg} \mathrm{~d}^{-1}\right)$. O programa alimentar alterou $(P<0,05)$ o balanço do $N$, mas não afetou $(P>0,05)$ a retenção de $N$ pelos animais. A alimentação à vontade alterou $(P<0,05)$ o balanço da energia, sobretudo a energia retida (3.825 vs. $\left.3.013 \mathrm{kcal} \mathrm{d}^{-1}\right)$. A adição de 0,5\% de bentonita sódica nas dietas reduziu em 9\% ( $P<0,01)$ a excreção fecal de fósforo. A adição de bentonita sódica nas dietas de suínos não altera os balanços da energia e do $N$ nem as digestibilidades aparentes do $\mathrm{Ca}, \mathrm{Mg}, \mathrm{Zn}, \mathrm{Cu}$ e $\mathrm{Mn}$. A adição de bentonita sódica reduz a excreção fecal de fósforo. Não há interação entre o programa alimentar e a adição de bentonita sódica nas dietas.

Palavras-chave: alimentação à vontade, alimentação restrita, argilas, minerais, nutrientes.

\section{ABSTRACT}

An experiment was carried out to evaluate the digestibility of diets and metabolism of pigs fed diets containing sodium bentonite subjected to different feeding programs.
Twenty-four barrows were used, littermates, $42.2 \mathrm{~kg}$ initial live weight, housed in metabolic cages. Experimental design was completely randomized with three sodium bentonite levels $(0.0$; 0.3 and $0.5 \%$ ) and two feeding programs (restricted and ad libitum), with eight replications each. Addition of sodium bentonite didn't affect $(P>0.05)$ the feed intake, the energy and $N$ balance. The feed intake differ $(P<0.01)$ between restricted and ad libitum feeding $\left(1.17 \mathrm{vs}\right.$. $\left.2.19 \mathrm{~kg} d^{-1}\right)$. The feeding program alter $(P<0.05)$ the $N$ balance, but don't affected $(P>0.05)$ the $N$ retention in pigs. Ad libitum feeding alter $(P<0.05)$ the energy balance, mainly the retained energy $\left(3,825 \mathrm{vs} .3,013 \mathrm{kcal} \mathrm{d}^{-1}\right)$. Addition of $0.5 \%$ of sodium bentonite in diets reduced in $9 \%$ $(P<0.01)$ the fecal phosphorus excretion. Sodium bentonite in diets doesn't alter the energy and $N$ balance neither apparent digestibility of $\mathrm{Ca}, \mathrm{Mg}, \mathrm{Zn}, \mathrm{Cu}$ and $\mathrm{Mn}$. Sodium bentonite in diets reduce the fecal phosphorus excretion. There is no interaction between the feeding program and the addition of sodium bentonite in diets.

Key words: ad libitum feeding, clays, minerals, nutrients, restricted feeding

\section{INTRODUÇÃO}

A utilização de argilas como adsorventes na prevenção de micotoxicoses é de uso comum na produção de suínos. Os aluminossilicatos, argilas compostas principalmente por silício e alumínio, apresentam alta afinidade por micotoxinas, as quais permanecem aderidas na estrutura da argila (LINDEMANN et al., 1993). A bentonita sódica, argila vulcânica da classe das esmectitas, apresenta alta

'Programa de Pós-graduação em Zootecnia, Universidade Federal de Santa Maria (UFSM), 97105-900, Santa Maria, RS, Brasil. Email: cheilalehnen@yahoo.com.br,*Autor para correspondência.

IIDepartamento de Zootecnia, UFSM, Santa Maria, RS, Brasil.

IIIFaculdade de Ciências Agrárias e Veterinárias, Universidade Estadual Paulista (UNESP), Jaboticabal, SP, Brasil. 
plasticidade, gelatinização e superfície específica (KOMINE \& OGATA, 2004). Devido à alta capacidade de retenção de água e redução da viscosidade da digesta, a bentonita sódica pode melhorar a digestibilidade dos nutrientes pelo aumento do tempo de retenção do alimento no trato gastrintestinal (CASTAING 1998).

Estudos com diferentes argilas indicam a interferência desses compostos na digestibilidade dos nutrientes no suíno. A sepiolita e clinoptilolita aumentam a retenção do $\mathrm{N}$ e redução na excreção de Nurinário (POULSEN\& OKSBJERG 1995; CASTAING $\&$ NOBLET, 1997). Estudos com sepiolita apresentam resultados contraditórios com redução na energia digestível e digestibilidade da MS (CASTAING \& NOBLET, 1997) e maior utilização da energia, MS e proteína (PARSINI et al., 1999). A complexação dos minerais com a argila no lúmen intestinal pode limitar a absorção e aumentar a excreção de minerais. Porém, as respostas obtidas no metabolismo mineral sobre os efeitos da bentonita sódica e de outras argilas têm sido variáveis (COLLINGS et al., 1980; SCHELL et al., 1993; CASTAING, 1998).

Os programas alimentares, como a restrição alimentar e alimentação à vontade, alteram o metabolismo dos nutrientes através de adaptações fisiológicas no animal. Na restrição alimentar, o sistema digestório ajusta sua massa à absorção dos nutrientes, alterando a secreção enzimática e aumentando a área absortiva do intestino delgado (POND \& MERSMANN, 1990). A alimentação restrita seguida de alimentação à vontade pode aumentar o ganho protéico em relação ao lipídico, reflexo da maior retenção de nitrogênio (FABIAN et al., 2004). Essa modulação fisiológica reduz o gasto energético e a oxidação de aminoácidos, aumentando a eficiência de síntese protéica (FABIAN et al., 2002).

Nesse contexto, as respostas fisiológicas dos diferentes programas alimentares no suíno podem interferir no comportamento de aluminossilicatos no trato gastrintestinal (SCHELL et al., 1993). Embora os efeitos de aluminossilicatos na prevenção de micotoxicoses em suínos sejam conhecidos, as respostas digestivas e metabólicas são pouco estudadas. Diante disso, este trabalho foi realizado com o objetivo de avaliar a digestibilidade das dietas e o metabolismo de suínos alimentados com dietas contendo bentonita sódica submetidos a diferentes programas alimentares.

\section{MATERIAL E MÉTODOS}

Foram utilizados 24 suínos machos castrados, geneticamente homogêneos e meio irmãos paternos, oriundos de cruzamentos industriais, com peso inicial de $42,2 \pm 2,4 \mathrm{~kg}$. Os animais foram alojados em gaiolas metabólicas, semelhantes às descritas por PEKAS (1968) e mantidos em ambiente controlado com temperatura média de $22^{\circ} \mathrm{C}$. O delineamento experimental foi o inteiramente casualisado com três níveis de bentonita sódica $(0,0 ; 0,3$ e $0,5 \%)$ e dois programas alimentares (restrito e à vontade) com oito repetições por tratamento.

As dietas experimentais (Tabela 1) foram formuladas utilizando o modelo e as recomendações nutricionais do InraPorc $^{\circledR}$ (INRAPORC, 2008). O experimento foi dividido em três fases com duração total de 21 dias, sendo cinco dias de adaptação dos animais às gaiolas e às dietas; oito de coleta para um período com alimentação restrita (Fase 1) seguida de oito de coleta para um período com alimentação à vontade (Fase 2). Após a alimentação restrita os mesmos animais foram submetidos à alimentação à vontade. Fase 1 "restrita" - o consumo foi calculado de acordo com o peso metabólico $\left(\mathrm{PV}^{0,60}\right)$, sendo ajustado

Tabela 1 - Composição centesimal das dietas experimentais ${ }^{1}$.

\begin{tabular}{|c|c|c|c|}
\hline \multirow{2}{*}{ Variáveis } & \multicolumn{3}{|c|}{------Bentonita sódica (\%)------ } \\
\hline & 0,0 & 0,3 & 0,5 \\
\hline Milho & 69,89 & 69,89 & 69,89 \\
\hline Farelo de soja & 22,23 & 22,23 & 22,23 \\
\hline Óleo vegetal & 3,87 & 3,87 & 3,87 \\
\hline Bentonita sódica & 0,00 & 0,30 & 0,50 \\
\hline Suplemento vitamínico e mineral ${ }^{2}$ & 4,00 & 4,00 & 4,00 \\
\hline Total & 100,00 & 100,30 & 100,50 \\
\hline -----------------------Composição & calculada- & & ------ \\
\hline Matéria seca $(\%)$ & 87,30 & 87,30 & 87,30 \\
\hline Energia bruta $\left(\mathrm{kcal} \mathrm{kg}^{-1}\right)$ & 3.859 & 3.859 & 3.859 \\
\hline Energia metabolizável $\left(\mathrm{kcal} \mathrm{kg}^{-1}\right)$ & 3.265 & 3.265 & 3.265 \\
\hline Proteína bruta (\%) & 20,0 & 20,0 & 20,0 \\
\hline Lisina $(\%)$ & 1,02 & 1,02 & 1,02 \\
\hline Metionina (\%) & 0,29 & 0,29 & 0,29 \\
\hline Treonina $(\%)$ & 0,74 & 0,74 & 0,74 \\
\hline Triptofano (\%) & 0,23 & 0,23 & 0,23 \\
\hline $\mathrm{Ca}(\%)$ & 1,47 & 1,47 & 1,47 \\
\hline $\mathrm{P}$ total $(\%)$ & 1,40 & 1,40 & 1,40 \\
\hline $\operatorname{Mg}(\%)$ & 0,27 & 0,27 & 0,27 \\
\hline $\mathrm{Zn}\left(\mathrm{mg} \mathrm{kg}^{-1}\right)$ & 149 & 149 & 149 \\
\hline $\mathrm{Cu}\left(\mathrm{mg} \mathrm{kg}^{-1}\right)$ & 166 & 166 & 166 \\
\hline $\operatorname{Mn}\left(\mathrm{mg} \mathrm{kg}^{-1}\right)$ & 65 & 65 & 65 \\
\hline
\end{tabular}

${ }^{1}$ Matéria natural, composição dos alimentos segundo Inraporc (2008); ${ }^{2}$ Suplemento vitamínico e mineral, composição por $\mathrm{kg}$ de produto: Vit. A, 60.000UI; Vit. B2, 40mg; Vit. B6, 20mg; Vit. B12, 200mg; Vit. D3, 12.000UI; Vit. E, 800mg; Ác. Pantotênico, 200mg; Cálcio, 200g; Fósforo, 50g; Sódio, 45g; Cobre, 160mg; Ferro, 1.100mg; Iodo, 6mg; Manganês, 200mg; Selênio, 5mg; Zinco, 1.400mg; Metionina, 1g; Lisina, 2g; Ácido Fólico, 10mg; Ácido Pantotênico, 200mg; Biotina, 2mg; Colina, 1.200mg; Niacina, 300mg. 
diariamente com base em um ganho médio diário estimado de $0,8 \mathrm{~kg}$, considerando um consumo de 2,6 vezes a mantença estimada em $250 \mathrm{kcal} \mathrm{EM} \mathrm{kg}^{-1} \mathrm{PV}^{0,60}$ (NOBLET et al., 1993). Fase 2 "à vontade" - o consumo foi estimado de acordo com o peso metabólico, considerando um consumo de $461 \mathrm{kcal} \mathrm{EM} \mathrm{kg}^{-1} \mathrm{PV}^{0,60}$ (NOBLET \& SHI, 1993). As dietas experimentais foram distribuídas em três refeições diárias: às 8,13 e 18 horas, sendo as sobras de ração pesadas, quantificadas ao final de cada dia e determinado seu conteúdo de matéria seca. Os animais tiveram livre acesso à água.

Foi utilizado o método de coleta total de fezes, sendo o início e o final das coletas determinados pelo aparecimento de fezes marcadas pela adição de $1,5 \%$ de $\mathrm{Fe}_{2} \mathrm{O}_{3}$ às dietas. As fezes foram coletadas, acondicionadas em sacos plásticos e conservadas em congelador a $-10^{\circ} \mathrm{C}$. No final de cada período, as fezes foram homogeneizadas e amostradas $(0,5 \mathrm{~kg})$, secas em estufa de ventilação forçada $\left(60^{\circ} \mathrm{C}\right.$ por 72 horas) e moídas para análises posteriores. A urina excretada foi drenada para baldes plásticos contendo $25 \mathrm{~mL}$ de $\mathrm{HCl}$ $6 \mathrm{~N}$. A cada $12 \mathrm{~h}$, o volume de urina foi quantificado, homogeneizado e uma amostra de 5\% retirada e conservada sob refrigeração a $4^{\circ} \mathrm{C}$. As análises químicas das dietas, fezes e urina foram realizadas segundo a metodologia proposta pela AOAC (1990). Foram avaliados o balanço de energia e $\mathrm{N}$, a digestibilidade de macro (Ca, $\mathrm{P}, \mathrm{Mg}$ ) e micro minerais ( $\mathrm{Zn}, \mathrm{Cu}$ e $\mathrm{Mn}$ ).

Os dados obtidos foram submetidos à análise de variância pelo procedimento GLM, segundo o modelo analítico $\mathrm{y}_{\mathrm{ij}}=\mu+\alpha_{\mathrm{BS}}+\beta_{\mathrm{PA}}+\alpha_{\mathrm{BS}} * \beta_{\mathrm{PA}}+\varepsilon_{\mathrm{ij}}$ em que $\mathrm{y}_{\mathrm{ijk}}$ são as variáveis dependentes; $\alpha_{\mathrm{BS}}$ efeito dos níveis de bentonita sódica; $\beta_{\mathrm{PA}}$ efeito do programa alimentar; $\alpha_{\mathrm{BS}} * \beta_{\mathrm{PA}}$ interação entre os efeitos avaliados e $\varepsilon_{\mathrm{ijk}}$ erro aleatório residual. As diferenças entre as médias foram comparadas pelo Teste de Tukey a $5 \%$ de probabilidade. As análises estatísticas foram realizadas através do MINITAB 15 (2007).

\section{RESULTADOS E DISCUSSÃO}

Os resultados para o balanço da energia são apresentados na tabela 2. Não houve interação $(P>0,05)$ entre a adição de bentonita sódica nas dietas e o programa alimentar. Dietas contendo bentonita sódica não alteraram $(\mathrm{P}>0,05)$ o consumo de ração e o balanço energético. $\mathrm{O}$ consumo de alimento e a ingestão de energia foram $28 \%$ superiores $(\mathrm{P}<0,01)$ na alimentação à vontade. As energias de mantença e retida foram $13 \mathrm{e}$ $26 \%$ superiores $(\mathrm{P}<0,01)$, respectivamente, em suínos alimentados à vontade.

Durante o período de restrição alimentar, ocorrem alterações na utilização dos nutrientes, devido ao consumo limitado de alimento através da redução de órgãos viscerais (POND \& MERSMANN, 1990). Esse ajuste é necessário para manter a homeostase no organismo animal. Na alimentação restrita, grande parte da energia ingerida é utilizada para as necessidades de mantença e as perdas energéticas durante a digestão do alimento são reduzidas (LOVATTO et al., 2006). No entanto, as exigências de mantença em suínos alimentados à vontade são maiores em função da maior ingestão de alimento, que aumenta a produção de calor através da atividade de órgãos metabolicamente ativos (CRITSER et al., 1995). Além disso, neste estudo, o peso metabólico dos animais na fase de alimentação à vontade foi superior em relação à fase restrita, o que aumenta as exigências de mantença.

Tabela 2 - Balanço da energia de suínos alimentados com dietas contendo bentonita sódica em dois programas alimentares.

\begin{tabular}{|c|c|c|c|c|c|c|c|c|}
\hline & \multirow{2}{*}{$\begin{array}{c}\mathrm{CAl}, \\
\mathrm{kg} / \mathrm{dia}^{1.1}\end{array}$} & \multicolumn{7}{|c|}{--1 } \\
\hline & & Ingerida & Fecal & Urinária & Mantença & Retida & ED & EM \\
\hline \multicolumn{9}{|c|}{-Bentonita sódica (BS) (\%)-- } \\
\hline BS 0,0 & 1,93 & 7.452 & 1.214 & 215 & 2.696 & 3.327 & 3.271 & 3.056 \\
\hline BS 0,3 & 1,98 & 7.718 & 1.283 & 197 & 2.676 & 3.560 & 3.275 & 3.078 \\
\hline BS 0,5 & 1,93 & 7.460 & 1.280 & 144 & 2.678 & 3.358 & 3.242 & 3.098 \\
\hline Restrito & 1,71 & 6.609 & 951 & 139 & 2.513 & 3.013 & 3.288 & 3.148 \\
\hline À vontade & 2,19 & 8.478 & 1.567 & 236 & 2.853 & 3.825 & 3.238 & 3.006 \\
\hline $\mathrm{epr}^{2}$ & 0,13 & 527 & 113 & 118 & 117 & 424 & 80 & 136 \\
\hline \multicolumn{9}{|c|}{---Probabilidade ${ }^{3}$} \\
\hline Bentonita sódica & 0,28 & 0,74 & 0,16 & 0,22 & 0,83 & 0,25 & 0,18 & 0,64 \\
\hline Programa alimentar & 0,01 & 0,01 & 0,02 & 0,03 & 0,01 & 0,01 & 0,06 & 0,06 \\
\hline $\mathrm{BS} * \mathrm{PA}$ & 0,24 & 0,71 & 0,15 & 0,28 & 0,95 & 0,29 & 0,96 & 0,38 \\
\hline
\end{tabular}

${ }^{1} \mathrm{CAl}$, consumo de alimento com base na matéria seca; ${ }^{2}$ erro-padrão residual; ${ }^{3}$ nível $5 \%$ de probabilidade. 
Na fase de alimentação à vontade, os animais podem utilizar os nutrientes com maior eficiência (FABIAN et al., 2002). Entretanto, em situações de períodos curtos de restrição alimentar e seguida de alimentação à vontade, a eficiência energética pode estar relacionada à recuperação da massa de órgãos digestivos (CRITSER et al., 1995) e não estar associada ao ganho compensatório (LOVATTO et al., 2006). Nesses casos, as respostas de ganho compensatório estão relacionadas com o ganho em água e de preenchimento com alimento no trato gastrintestinal.

Adicionalmente, a superfície específica da bentonita sódica pode interferir na recaptação da água do bolo alimentar, contribuindo com a digestibilidade dos nutrientes através do aumento do conteúdo de matéria seca no trato gastrintestinal (CASTAING, 1998). Além disso, a adição dessas argilas na dieta pode aumentar a atividade enzimática, estimulada pelo aumento das secreções gastrintestinais (XIA et al., 2004).

Os resultados da proteína digestível e do balanço do nitrogênio são apresentados na tabela 3 . Não houve interação $(\mathrm{P}>0,05)$ entre a adição de bentonita sódica nas dietas e o programa alimentar. Dietas contendo bentonita sódica não alteraram $(\mathrm{P}>0,05)$ a proteína digestível e o balanço do nitrogênio. O programa alimentar afetou $(\mathrm{P}<0,05)$ a proteína digestível e as variáveis $\mathrm{N}$ ingerido, $\mathrm{N}$ fecal, $\mathrm{N}$ urinário e $\mathrm{N}$ absorvido. No entanto, o $\mathrm{N}$ retido não diferiu $(\mathrm{P}>0,05)$ entre o fornecimento restrito e à vontade.

Suínos alimentados à vontade, após um período de restrição de nutrientes, apresentam maior retenção de nitrogênio (FABIAN et al., 2004). A utilização desse nutriente está envolvida na reposição de $\mathrm{N}$ pelos órgãos viscerais metabolicamente ativos (FABIAN et al., 2002). Na restrição quali ou quantitativa, o organismo ajusta a massa visceral à disponibilidade de nutrientes (POND \& MERSMANN, 1990). Além disso, a eficiência na utilização de nutrientes pode estar relacionada ao tempo e à intensidade de restrição (LOVATTO et al., 2000). É provável que a intensidade de restrição utilizada e a sua duração foram insuficientes para alterar a massa de órgãos do sistema digestório.

A bentonita sódica, por apresentar alta capacidade de troca de cátions, pode contribuir na captação de íons $\mathrm{NH}_{4}{ }^{+}$, que se ligam facilmente à superfície negativa da argila. Dessa forma, pode ocorrer a redução na absorção e transformação de amônia em ureia, o que aumenta a concentração de $\mathrm{N}$ fecal e reduz a excreçãode Nurinário(POULSEN\& OKSBJERG 1995). Embora não tenham sido verificadas alterações significativas no balanço do nitrogênio foi observada menor excreção urinária e fecal em animais alimentados com dietas contendo bentonita sódica.

Os resultados de digestibilidade aparente de macro minerais são apresentados na tabela 4 . Não houve interação $(\mathrm{P}>0,05)$ entre a adição de bentonita sódica nas dietas e o programa alimentar sobre a digestibilidade aparente de macro e micro minerais. Os níveis de bentonita sódica não alteraram $(\mathrm{P}>0,05)$ a digestibilidade aparente dos minerais $\mathrm{Ca}$ e Mg. A adição de $0,5 \%$ de bentonita sódica reduziu em $9 \%(\mathrm{P}<0,01)$ a excreção fecal de fósforo em relação ao tratamento sem bentonita sódica. É provável que a retenção do alimento no trato gastrintestinal, associada ao aumento da

Tabela 3 - Proteína digestível aparente e balanço do nitrogênio em suínos alimentados com dietas contendo bentonita sódica em dois programas alimentares.

\begin{tabular}{|c|c|c|c|c|c|c|}
\hline & $\mathrm{PD}_{\mathrm{a}}\left(\%^{1}\right)$ & Ingerido & Fecal & Urinário & Absorvido & Retido \\
\hline \multicolumn{7}{|c|}{ 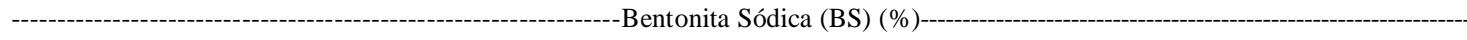 } \\
\hline BS 0,0 & 17,64 & 61,73 & 7,13 & 24,28 & 55,34 & 31,06 \\
\hline BS 0,3 & 17,77 & 63,91 & 6,81 & 20,00 & 55,66 & 35,67 \\
\hline BS 0,5 & 17,66 & 61,79 & 7,09 & 16,19 & 55,38 & 39,18 \\
\hline & & -------Pr & liment: & -1-- & & - \\
\hline Restrito & 17,58 & 54,73 & 6,51 & 15,24 & 48,22 & 32,98 \\
\hline À vontade & 17,80 & 70,22 & 7,50 & 25,08 & 62,71 & 37,63 \\
\hline $\mathrm{epr}^{2}$ & 2,67 & 4,35 & 1,36 & 13,01 & 4,31 & 11,99 \\
\hline Bentonita sódica & 0,90 & 0,28 & $\begin{array}{l}\text { billidad } \\
0,92\end{array}$ & 0,20 & 0,22 & 0,17 \\
\hline Programa alimentar & 0,01 & 0,01 & 0,02 & 0,01 & 0,01 & 0,18 \\
\hline $\mathrm{BS} * \mathrm{PA}$ & 0,82 & 0,24 & 0,27 & 0,26 & 0,47 & 0,25 \\
\hline
\end{tabular}

${ }^{1} \mathrm{PD}_{\mathrm{a}}$, proteína digestível aparente; ${ }^{2}$ erro-padrão residual; ${ }^{3}$ nível de $5 \%$ de probabilidade 
Tabela 4 - Digestibilidade aparente de macro minerais em suínos alimentados com dietas contendo bentonita sódica em dois programas alimentares.

\begin{tabular}{|c|c|c|c|c|c|c|c|c|c|}
\hline \multirow{2}{*}{ Variáveis } & \multicolumn{3}{|c|}{-----Bentonita sódica (BS) (\%)----- } & \multicolumn{3}{|c|}{------Programa alimentar (PA)------ } & \multicolumn{3}{|c|}{------- Probabilidade ${ }^{2}$------- } \\
\hline & 0,0 & 0,3 & 0,5 & RE & AV & epr $^{1}$ & BS & PA & $\mathrm{BS} * \mathrm{PA}$ \\
\hline \multicolumn{10}{|c|}{ - } \\
\hline Ingerido & 27,13 & 28,10 & 27,16 & 24,06 & 30,86 & 1,92 & 0,28 & 0,01 & 0,23 \\
\hline Fecal & 11,02 & 11,61 & 10,13 & 9,75 & 12,08 & 1,37 & 0,01 & 0,01 & 0,48 \\
\hline Absorvido & 16,10 & 16,49 & 17,03 & 14,30 & 18,79 & 1,84 & 0,37 & 0,01 & 0,67 \\
\hline & & & & ----Cál & $\left.\mathrm{dia}^{-1}\right)$ & & & & --- \\
\hline Ingerido & 28,95 & 30,09 & 28,63 & 25,65 & 32,80 & 2,17 & 0,15 & 0,01 & 0,19 \\
\hline Fecal & 4,50 & 4,26 & 4,02 & 3,78 & 4,74 & 1,03 & 0,42 & 0,01 & 0,69 \\
\hline Absorvido & 24,45 & 25,83 & 24,62 & 21,87 & 28,06 & 1,88 & 0,09 & 0,01 & 0,25 \\
\hline & & & & - -Mag & $\mathrm{g} \mathrm{dia}^{-1}$ & & & & --- \\
\hline Ingerido & 5,31 & 5,52 & 5,32 & 4,56 & 6,21 & 0,47 & 0,37 & 0,01 & 0,32 \\
\hline Fecal & 1,87 & 2,05 & 1,92 & 1,71 & 2,19 & 0,68 & 0,74 & 0,02 & 0,87 \\
\hline Absorvido & 3,44 & 3,47 & 3,39 & 2,85 & 4,02 & 0,82 & 0,96 & 0,01 & 0,43 \\
\hline
\end{tabular}

RE - Restrito; AV - À vontade; ${ }^{1}$ erro-padrão residual; ${ }^{2}$ nível de 5\% de probabilidade.

capacidade de expansão em meio aquoso da bentonita sódica, tenha aumentado a superfície absortiva e, consequentemente, gerou maior absorção do fósforo pelo animal. Argilas com características semelhantes às da bentonita corroboram os resultados obtidos, indicando a maior utilização dos nutrientes e minerais pelo animal (CASTAING, 1998). Dietas contendo bentonita sódica não alteraram $(\mathrm{P}>0,05)$ a digestibilidade aparente dos micro minerais (Tabela 5). No entanto, a alimentação de suínos de forma restrita e à vontade alterou $(\mathrm{P}<0,05)$ a digestibilidade aparente do $\mathrm{Zn}, \mathrm{Cu}$ e $\mathrm{Mn}$. As alterações verificadas na digestibilidade de minerais em suínos alimentados com dietas à vontade são influenciadas pelo aumento na ingestão de nutrientes. $\mathrm{O}$ fornecimento à vontade das dietas aumentou, em média, $28 \%(\mathrm{P}<0,01)$ a ingestão de macro e micro minerais. Dessa forma, o aumento na absorção está diretamente relacionado ao maior consumo de ração.

A adição de bentonita sódica nas dietas pode alterar a digestibilidade dos minerais. As interferências no balanço mineral estão relacionadas à capacidade de trocas catiônicas da bentonita sódica, referentes à carga e à valência dos íons em solução e ainda ao $\mathrm{pH}$ no meio aquoso (AGUIAR \& NOVAES, 2002). Os íons de maior valência são fortemente

Tabela 5 - Digestibilidade aparente de micro minerais em suínos alimentados com dietas contendo bentonita sódica em dois programas alimentares.

\begin{tabular}{|c|c|c|c|c|c|c|c|c|c|}
\hline \multirow{2}{*}{ Variáveis } & \multicolumn{3}{|c|}{-----Bentonita sódica (BS) (\%)----- } & \multicolumn{3}{|c|}{-----Programa alimentar (PA) ----- } & \multicolumn{3}{|c|}{-------Probabilidade'------- } \\
\hline & 0,0 & 0,3 & 0,5 & $\mathrm{RE}$ & AV & epr $^{1}$ & BS & PA & $\mathrm{BS} * \mathrm{PA}$ \\
\hline \multicolumn{10}{|c|}{ - } \\
\hline Ingerido & 298 & 299 & 291 & 260 & 333 & 21 & 0,54 & 0,01 & 0,26 \\
\hline Fecal & 201 & 193 & 176 & 171 & 209 & 33 & 0,11 & 0,01 & 0,46 \\
\hline Absorvido & 97 & 106 & 115 & 88 & 123 & 37 & 0,44 & 0,01 & 0,78 \\
\hline & & & & $-\mathrm{Col}$ & $\left.\mathrm{dia}^{-1}\right)$ & & & & \\
\hline Ingerido & 315 & 320 & 341 & 278 & 357 & 29 & 0,10 & 0,01 & 0,85 \\
\hline Fecal & 102 & 106 & 109 & 126 & 86 & 40 & 0,87 & 0,01 & 0,97 \\
\hline Absorvido & 213 & 214 & 231 & 152 & 270 & 51 & 0,07 & 0,01 & 0,89 \\
\hline & & & & Mang & $\mathrm{g} \mathrm{dia}^{-1}$ & & & & \\
\hline Ingerido & 125 & 124 & 119 & 121 & 158 & 11 & 0,25 & 0,01 & 0,27 \\
\hline Fecal & 77 & 80 & 73 & 74 & 94 & 14 & 0,28 & 0,01 & 0,96 \\
\hline Absorvido & 47 & 43 & 46 & 46 & 64 & 13 & 0,66 & 0,01 & 0,53 \\
\hline
\end{tabular}

RE - Restrito; AV - À vontade; ${ }^{1}$ erro-padrão residual; ${ }^{2}$ nível de $5 \%$ de probabilidade.

Ciência Rural, v.41, n.12, dez, 2011. 
atraídos pela superfície da argila. No entanto, as altas variações de $\mathrm{pH}$ podem dissociar as estruturas da argila e impedir a adsorção de elementos à superfície (AGUIAR \& NOVAES, 2002). No entanto, não foram observadas interações entre a bentonita sódica e o programa alimentar, as quais poderiam interferir no balanço mineral através do aumento da excreção fecal de nutrientes.

A bentonita sódica e a alimentação restrita e à vontade interferem, isoladamente, na digestibilidade dos nutrientes. Nesse sentido, a restrição alimentar pode contribuir com ajustes sem afetar negativamente o desempenho animal. Entretanto, são necessários estudos em digestibilidade com argilas e com níveis de restrições variados, com o objetivo de ajustar a oferta de nutrientes e verificar suas respostas sobre a digestão e absorção em suínos.

\section{CONCLUSÃO}

A adição de bentonita sódica nas dietas não altera o balanço da energia, do nitrogênio e a digestibilidade aparente do cálcio, magnésio, zinco, cobre e manganês. A bentonita sódica reduz a excreção fecal de fósforo. Não há interação entre o programa alimentar e a adição de bentonita sódica nas dietas sobre a digestibilidade dos nutrientes.

\section{REFERÊNCIAS}

AGUIAR, M.R.; NOVAES, A.C. Remoção de metais pesados de efluentes industriais por aluminossilicatos. Química Nova, v.25, p.1145-1154, 2002. Disponível em: <http://www.scielo.br/ scielo.php ? script = sci a rttext \& pid=S 0100 40422002000700015>. Acesso em: 10 fev. 2009. doi: 10.1590/ S0100-40422002000700015.

AOAC. Official methods of analysis. 15.ed. Arlington: Kenneth Helrich, 1990. V.2, 1298p.

CASTAING, J. Uso de las arcillas en alimentación animal. In: CURSO DE ESPECIALIZACIÓN VANCES EN NUTRICIÓN Y ALIMENTACIÓN ANIMAL, 14., 1998, Fira de Barcelona, Espanha. Anais... Fira de Barcelona: Fundación Española para el Desarrollo de la Nutrición Animal, 1998, p.141-158. Disponível em: <http://www.etsia.upm.es/fedna/capitulos/ 98CAPVIII.pdf $>$. Acesso em: 23 dez. 2008

CASTAING, J.; NOBLET, J. Conséquences de l'introduction des sépiolite sur l'utilisation digestive de l'aliment et les performances du porc en croissance. Journées Recherche Porcine en France, v.29,p.213-220, 1999.

COLLINGS, G.F. et al. Sodium bentonite in swine diets. Journal of Animal Science, v.50, p.272-277, 1980. Disponível em: <http://jas.fass.org/cgi/reprint/50/2/272.pdf〉. Acesso em: 23 mar. 2009.
CRITSER, D.J. et al. The effects of dietary protein concentration on compensatory growth in barrows and gilts. Journal of Animal Science, v.73, p.3376-3383, 1995. Disponível em: <http://jas.fass.org/cgi/reprint/73/11/3376>. Acesso: 26 out. 2008 .

FABIAN, J. et al. Compensatory growth and nitrogen balance in grower-finisher pigs. Journal of Animal Science, v.82, p.2579-2587, 2004. Disponível em: <http://jas.fass.org/cgi/ reprint/82/9/2579>. Acesso em: 05 mar. 2009.

FABIAN, J. et al. Degree of amino acid restrictions during the grower phase and compensatory growth in pigs selected for lean growth efficiency. Journal of Animal Science, v.80, p.2610-2618, 2002. Disponível em: <http://jas.fass.org/cgi/ reprint/80/10/2610>. Acesso em: 22 jan. 2009.

KOMINE, H.; OGATA, N. Predicting swelling characteristics of bentonites. Journal of Geotechnical and Geoenvironmental Engineering, v.130, p.818-829, 2004. Disponível em: <http:// wwwgeo.civil.ibaraki.ac.jp/komine/mypapers/ ASCEKomine2004.pdf>. Acesso em: 6 nov. 2008. doi: 10.1061/ (ASCE)1090-0241(2004)130:8(818).

INRAPORC. A tool to evaluate nutritional strategies in pigs. 2008. Disponível em: 〈http://w3.rennes.inra.fr/inraporc/>. Acesso em: 22 out. 2008 .

LINDEMANN, M.D. et al. Potential ameliorators of aflatoxicosis in weanling/growing swine. Journal of Animal Science, v.71, p.171-178, 1993. Disponível em: <http:// jas.fass.org/cgi/reprint/71/1/171.pdf>. Acesso em: 12 dez. 2008.

LOVATTO, P.A. et al. Étude et modélisation du phénomène de croissance compensatrice chez le porc. Journées Recherche Porcine en France v.32, p.241-246, 2000. Disponível em: <http://www.journees-recherche-porcine.com/texte/2000/ 00txtAlim/A0011.pdf>. Acesso em: 20 mar. 2009.

LOVATTO, P.A. et al. Effects of feed restriction and subsequent refeeding on energy utilization in growing pigs. Journal of Animal Science, v.84, p.3329-3336, 2006. Disponível em: <http:// jas.fass.org/cgi/reprint/84/12/3329>. Acesso em: 26 jan. 2009.

MINITAB. User's guide: meet Minitab 15, Stat College, PA, Minitab Inc. 2007. 142p.

NOBLET, J; SHI, X.S. Comparative digestibility of energy and nutrients in growing pigs fed ad libitum and adult sows fed at maintenance. Livestock Production Science, v.34, p.137$152,1993$.

PARISINI, P. et al. Protein and energy retention in pigs fed diets containing sepiolite. Animal Feed Science and Technology, v.79, p.155-162, 1999. Disponível em: <http:// www.animalfeedscience.com/article/PIIS0377840199000085/ fulltext>. Acesso em: 23 dez. 2010.

PEKAS, J.C. Versatile swine laboratory apparatus for physiologic and metabolic studies. Journal of Animal Science, v.27, p.1303-1306, 1968. Disponível em: <http://jas.fass.org/cgi/ reprint/27/5/1303.pdf $>$. Acesso em: 15 dez. 2008.

POND, W.G.; MERSMANN, H.J. Differential compensatory growth in swine following control of feed intake by a high-alfalfa diet fed ad libitum or by limited feed. Journal of Animal 
Science, v.68, p.352-362, 1990. Disponível em: <http:// jas.fass.org/cgi/reprint/68/2/352>. Acesso em: 24 mar. 2009.

POULSEN, H.D.; OKSBJERG, N. Effects of dietary inclusion of a zeolite (clinoptilolite) on performance and protein metabolism of young growing pigs. Animal Feed Science and Technology, v.53, p.297-303, 1995. Disponível em: <http://www.ingentaconnect.com/content/els/03778401/1995/ 00000053/00000003/art00744> Acesso em: 15 fev. 2009. doi: 10.1016/0377-8401(94)00744-T.

SCHELL, T.C. et al. Effectiveness of different types of clay for reducing the detrimental effects of aflatoxin-contaminated diets on performance and serum profiles of weanling pigs. Journal of Animal Science, v.71, p.1226-1231, 1993. Disponível em: 〈http://jas.fass.org/cgi/reprint/71/5/1226>. Acesso em: 13 fev. 2009.

XIA, M.S. et al. Effects of copper-bearing montmorillonite on growth performance, digestive enzyme activities, and intestinal microflora and morphology of male broilers. Animal Feed Science and Technology, v.83, p.1868-1875, 2004. Disponível em: <http://ps.fass.org/cgi/reprint/83/11/1868>. Acesso em: 04 out. 2009. 